\title{
Peertechz
}

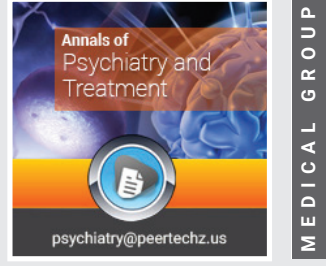

\section{First case series of clozapine induced hypogammaglobulinaemia in England}

\author{
S Elkhalifa ${ }^{1 *}$, T Garcez², S Drinkwater ${ }^{2}$, T Tan¹, \\ P Vijayadurai ${ }^{3}$, A Anantharachagan ${ }^{3}$, A Herwadkar ${ }^{1}$, \\ H Alachkar ${ }^{4}$ and J Darroch ${ }^{4}$ \\ 1Salford Royal NHS Foundation Trust, England \\ ${ }^{2}$ Manchester University NHS Foundation trust, England \\ ${ }^{3}$ Lancashire Teaching Hospitals NHS Foundation Trust, England \\ ${ }^{4}$ Royal Liverpool and Broadgreen University Hospitals NHS Trust, England
}

Received: 16 February, 2021

Accepted: 17 March, 2021

Published: 18 March, 2021

*Corresponding author: Dr. Shuayb Elkhalifa, Consultant Immunologist, Salford Royal NHS Foundation Trust, Salford Care Organisation, Honorary Lecturer, Faculty of Biology, Medicine and Health, University of Manchester, England,

E-mail: shuayb.elkhalifa@srft.nhs.uk; shuayb. elkhalifa@manchester.ac.uk

Keywords: Clozapine; Hypogammaglobulinaemia; Phosphatidylinositol-3-kinase; Humoral immune deficiency; B cells

https://www.peertechzpublications.com

\section{Check for updates}

\section{Abstract \\ Evidence is emerging that clozapine can adversely affect immunoglobulin levels. We present a case series of 17 clozapine-treated patients referred to clinical immunology centres in the north west of England with otherwise-unexplained hypogammaglobulinaemia. This adds to existing evidence and suggests that clozapine can cause clinically significant antibody deficiency that will sometimes require specialist intervention. We speculate that this putative drug toxicity could be mediated via interaction with PI3K (phosphatidylinositol-3-kinase) signalling pathways involved in the development and homeostasis of B cells. It may be advisable to monitor immunoglobulin levels in patients being treated with clozapine.}

\section{Introduction}

Schizophrenia is a debilitating psychiatric condition and clozapine is recommended for patients who are unresponsive to, or intolerant of, conventional antipsychotic drugs [1]. Clozapine has numerous possible side-effects, ${ }^{1}$ among which neutropenia and fatal agranulocytosis are well-documented [2]. More recently, an association between clozapine treatment and hypogammaglobulinaemia has been reported [3].

Among four clinical immunology centres in the north west of England, we identified 17 clozapine-treated patients who were referred with hypogammaglobulinaemia for which there was no other likely cause. We describe the clinical and immunological phenotypes of these patients, and their management. Additionally, we speculate that a possible mechanism for this drug side-effect is interaction with PI3 kinase pathways involved in the development and maturation of B cells.

\section{Aim}

To review the diagnosis and management of hypogammaglobulinaemia in patients on long-term clozapine treatment.

\section{Method}

Retrospective review of medical notes and electronic patient records was undertaken to obtain information on the following:

1. Demographics

2. Immunoglobulin levels (IgG, IgA \& IgM), serum electrophoresis and immunofixation

3. Lymphocytes subsets (CD4, CD8, CD19 and CD16/56)

4. Specific antibody serology and response to vaccination, when relevant.

5. Mannose binding lectin (MBL) levels. 
6. Susceptibility to infections, microbiology results and nature of infections

7. Infection-related complications, such as bronchiectasis

8. Other clinical features and co-morbidities

9. Treatment strategies:
a) Prophylactic antibiotics
b) Immunoglobulin replacement

Data were anonymised.

\section{Results}

Data for the 17 patients is summarised in Tables 1,2:

\section{Demographic data and duration of clozapine therapy:}

Mean age was 43.7 years (range 29-60 years). Mean duration of clozapine treatment prior to referral was 8 years (range 2-15 years). Clozapine was stopped in two patients.

\section{Immunoglobulin levels:}

All 17 patients had panhypogammaglobulinaemia (all Immunoglobulin isotypes low or absent) at referral, or developed panhypogammaglobulinaemia while being followed up.

Mean immunoglobulin levels at referral were:

IgG $2.96 \mathrm{~g} / \mathrm{L}$ (range $1.12-5.30 \mathrm{~g} / \mathrm{L}$ )

IgM $0.06 \mathrm{~g} / \mathrm{L}$ (range $<0.01-0.37 \mathrm{~g} / \mathrm{L}$ )

IgA $0.29 \mathrm{~g} / \mathrm{L}$ (range $<0.07-0.91 \mathrm{~g} / \mathrm{L}$ )

One patient had a monoclonal paraprotein, deemed to be monoclonal gammopathy of uncertain significance (MGUS).
Susceptibility to infection, microbiology results and types of infections:

12 patients $(70 \%)$ were prone to recurrent sinopulmonary infections, with one requiring multiple admissions to the intensive care unit (ICU).

Pathogens commonly isolated were haemophilus, moraxella and pseudomonas spp.

Bronchiectasis was diagnosed in 3 patients (18\%).

Haemophilus influenzae, tetanus \& pneumococcal vaccination and serology:

11 patients (65\%) responded poorly to both polysaccharide and conjugated pneumococcal vaccines, and 2 patients (12\%) lost their pneumococcal protection during follow-up.

10 patients $(59 \%)$ responded poorly to haemophilus vaccine, of whom $9(53 \%)$ also responded poorly to tetanus vaccine.

\section{Lymphocytes subsets:}

16 patients (94\%) showed total lymphocyte counts within the normal reference range.

Lymphocyte subsets were variable:

- All lymphocyte subsets were low in one patient with lymphoid hyperplasia.

- The CD8 count was low in 3 patients:

oL6: treated for granulomatous lung disease, most likely to be granulomatous interstitial lung disease secondary to immunodeficiency.

Table 1: Laboratory findings for 17 clozapine-treated patients with hypogammaglobulinaemia

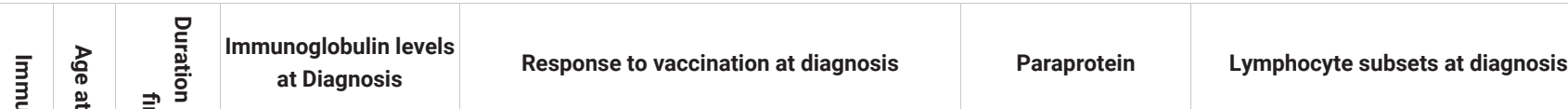
at Diagnosis

L1 42

L2 44

15

$\begin{array}{cc}4.87 & 0.33 \\ 4.8 & 0.73\end{array}$

$\begin{array}{lll}2.9 & 0.29 & 0.06\end{array}$

$\begin{array}{lll}1.8 & 0.09 & 0.08\end{array}$

$\begin{array}{lll}2.3 & 0.38 & 0.07\end{array}$

$\begin{array}{lll}2.8 & 0.1<0.04\end{array}$

$\begin{array}{lll}3.6 & 0.28 & 0.06\end{array}$

$\begin{array}{lll}2.62 & 0.07<0.04\end{array}$

$\begin{array}{lll}2.65 & 0.14 & 0.06\end{array}$

$\begin{array}{lll}4.62 & 0.09 & 0.07\end{array}$

$\begin{array}{lll}1.12 & 0.05<0.07\end{array}$

$\begin{array}{lll}4.5 & 0.59 & 0.23\end{array}$

$\begin{array}{lll}2.66 & 0.67<0.1\end{array}$

$\begin{array}{ll}5.2 & 0.39\end{array}$

$<0.1$

$\begin{array}{lll}3.06 & 0.33 & 0.12\end{array}$

0.12
$<0.05$

Hib Vaccine

\section{Tetanus \\ Pneumococcal}

vaccine

vaccines

intact lg

\begin{tabular}{l|c|c|c|c|} 
light & CD4 & CD8 & CD19 & CD16/56 \\
chain & $(0.430-$ & $(0.250-$ & $(0.120-$ & $(0.200-$
\end{tabular}

\begin{tabular}{|l|l|l|l|l|}
\hline only & $1.820)$ & $1.200)$ & $0.670)$ & $1.200)$
\end{tabular}

$M B L$

$(\mathrm{mg} / \mathrm{l})$

$1.00-$

Satisfactory Satisfactory Satisfactory

Satisfactory

Satisfactory

Satisfactory

Satisfactory

Satisfactory Satisfactory*

Satisfactory Satisfactory Unsatisfactory

Unsatisfactory Unsatisfactory Unsatisfactory

Satisfactory Satisfactory Satisfactory

Satisfactory Satisfactory Satisfactory

Unsatisfactory Unsatisfactory Unsatisfactory

Unsatisfactory Unsatisfactory Unsatisfactory IgG kappa

Unsatisfactory Unsatisfactory Unsatisfactory

Unsatisfactory Unsatisfactory Unsatisfactory

Satisfactory Satisfactory Satisfactory*

Unsatisfactory Unsatisfactory Unsatisfactory

Unsatisfactory Satisfactory Unsatisfactory

Unsatisfactory Unsatisfactory Unsatisfactory

P1 54

1.940 .19

Unsatisfactory Unsatisfactory Unsatisfactory

P3 40

$1.29 \quad 0.14$

$<0.05$ Unsatisfactory Unsatisfactory Unsatisfactory

U: unknown, N: negative/no.

Citation: Elkhalifa S, Garcez T, Drinkwater S, Tan T, Vijayadurai P, et al. (2021) First case series of clozapine induced hypogammaglobulinaemia in England. Ann Psychiatry Treatm 5(1): 015-018. DOI: https://dx.doi.org/10.17352/apt.000025 


\begin{tabular}{|c|c|c|c|c|c|c|c|}
\hline $\begin{array}{l}\text { Immunology } \\
\text { centre }\end{array}$ & $\begin{array}{l}\text { Age at first } \\
\text { diagnosis }\end{array}$ & $\begin{array}{c}\text { Clinically } \\
\text { infection-prone }\end{array}$ & $\begin{array}{c}\text { Site of } \\
\text { infection }\end{array}$ & Bronchiectasis & other clinical features & Ig replacement & Prophylactic Antibiotics \\
\hline L1 & 42 & $\mathrm{~N}$ & $\mathrm{n} / \mathrm{a}$ & not suspected & none & $\mathrm{N}$ & $\mathrm{N}$ \\
\hline L2 & 44 & $\mathrm{~N}$ & $\mathrm{n} / \mathrm{a}$ & not suspected & none & $\mathrm{N}$ & $\mathrm{N}$ \\
\hline L3 & 48 & Y & chest & N & none & $\mathrm{N}$ & $\mathrm{N}$ \\
\hline L4 & 57 & Y & chest & Y & none & Y & $\mathrm{N}$ \\
\hline L5 & 60 & $\mathrm{~N}$ & $\mathrm{n} / \mathrm{a}$ & $\mathrm{N}$ & lymphoid hyperplasia & $\mathrm{N}$ & $\mathrm{N}$ \\
\hline L6 & 41 & Y & chest & $\mathrm{N}$ & $\begin{array}{c}\text { granulomas, possible sarcoid like syndrome, } \\
\text { empyema }\end{array}$ & Y & Y \\
\hline L7 & 48 & Y & chest & Y, COPD, smoker & laryngeal dysplasia (benign) & $\mathrm{N}$ & $\mathrm{N}$ \\
\hline S1 & 49 & Y & chest & N & $\begin{array}{l}\text { iron deficiency anaemia, heart failure, chronic } \\
\text { renal failure }\end{array}$ & Y & $\mathrm{N}$ \\
\hline S2 & 48 & Y & chest & $\mathrm{N}$ & $\begin{array}{c}\text { granulomatous disease, ITU admissions with } \\
\text { sepsis }\end{array}$ & Y & Y \\
\hline S3 & 31 & Y & chest & $\mathrm{N}$ & IDDM, chronic diarrhoea & $\mathrm{N}$ & Y \\
\hline S4 & 40 & Y & chest & $\mathrm{N}$ & none & $Y * *$ & Y \\
\hline S5 & 35 & Y & chest & N & none & $\mathrm{N}$ & $\mathrm{N}$ \\
\hline M1 & 29 & Y & chest & $\mathrm{N}$ & none & Y & $\mathrm{N}$ \\
\hline M2 & 40 & Y & chest & N & none & $\mathrm{N}$ & $\mathrm{N}$ \\
\hline P1 & 54 & $\mathrm{~N}$ & $\mathrm{n} / \mathrm{a}$ & $\mathrm{N}$ & none & $\mathrm{N}$ & $\mathrm{N}$ \\
\hline P2 & 56 & N & $\mathrm{n} / \mathrm{a}$ & N & panlymphocytopenia & $\mathrm{N}$ & $\mathrm{N}$ \\
\hline P3 & 40 & Y & chest & Y & Hodgkin's lymphoma with relapse & Y & Y \\
\hline
\end{tabular}

Y: yes, N: negative/no, n/a: not applicable, COPD: Chronic Obstructive Pulmonary Disease, Y**: This patient has been on and off immunoglobulin.

\section{oL7: treated for benign laryngeal dysplasia.}

oS2: investigated for splenomegaly and multiple enlarged lymph nodes deemed reactive in nature and most likely related to underlying immunodeficiency.

- Isolated low B cells were found in two patients. One required immunoglobulin replacement therapy; the other has no apparent susceptibility to infection, despite unsatisfactory responses to all vaccines (pneumococcal, haemophilus and tetanus).

- NK cells (CD16/56) were reduced in 7 patients. One was treated for refractory Hodgkin's lymphoma.

\section{Other immunological investigations:}

Mannose binding lectin (MBL) was found to be low in 3 of the 5 patients tested $(60 \%)$.

\section{Treatment strategies:}

7 patients $(40 \%)$ required immunoglobulin replacement therapy. Another 5 patients (29\%) with recurrent infections required long-term antibiotic prophylaxis.

\section{Other clinical features and co-morbidities:}

The following were each observed in 1 patient (6\%):

- granulomatous interstitial lung disease

- splenomegaly and lymphadenopathy

- chronic diarrhoea (salmonella-positive), with insulindependent diabetes, and pancreatic insufficiency
- laryngeal dysplasia

- lymphoid hyperplasia

- Hodgkin's lymphoma

- chronic obstructive pulmonary disease (COPD)

- monoclonal gammopathy of uncertain significance (MGUS)

\section{Discussion}

We describe 17 clozapine-treated patients referred with hypogammaglobulinaemia for which no other cause was evident.

In a study exploring the use of decreased total serum globulins as a surrogate marker for hypogammaglobulinaemia, 4 of 32 primary care patients found to be hypogammaglobulinaemic were being treated with clozapine [4]. A subsequent comparison between clozapine-treated and clozapine-naïve patients confirmed an associated with hypogammaglobulinaemia, noting increased antibiotic usage and hospital admissions in the clozapine-treated group. The extent of the hypogammaglobulinaemia correlated with the duration of clozapine treatment [3]. The same group have reported the clinical and laboratory characteristics of clozapine-treated patients with schizophrenia referred to a national immunodeficiency clinic revealling a B-cell signature resembling common variable immunodeficiency (CVID) [5].

Our report is the first demonstration in England that clozapine-treated patients do present to specialist immunology 
clinics with hypogammaglobulinaemia and clinically significant antibody deficiency requiring specialist intervention. The effect may sometimes be reversible: of the two patients whose clozapine was discontinued, one showed complete recovery of all immunoglobulin isotypes 6 months later, with good vaccination responses; however, the other showed only partial recovery of immunoglobulins, with on-going poor antibody responses and continuing infection.

There is evidence that the therapeutic effect of clozapine might depend on interaction with phosphatidylinositol-3kinase (PI3K) pathways [6-8]. Furthermore, PI3K signalling pathways are essential for the development and homeostasis of B cells $[9,10]$. Additionally, inherited defects of PI3K signalling result in immunodeficiency [11]. Speculatively, therefore, altered function of PI3K pathways may be a mechanism for clozapine toxicity.

\section{Suggestions \& Conclusion}

The need to monitor clozapine-treated patients for toxic effects on granulocytes is well-established. New evidence suggests that it might also be prudent to monitor immunoglobulin levels and maintain clinical vigilance for infection with polysaccharide-encapsulated organisms (which are of particular relevance to antibody deficiency).

While there is tentative evidence that these changes may sometimes be reversible, the balance of risks may favour continuation of clozapine in patients who develop antibody deficiency. Ancillary treatments (e.g. antibiotics for acute infection, antibiotic prophylaxis, immunoglobulin replacement) may then become necessary.

Further research would be required to elucidate the mechanism of these effects.

\section{References}

1. Lewis SW, Davies L, Jones PB, Barnes TR, Murray RM, et al. (2006) Randomised controlled trials of conventional antipsychotic versus new atypical drugs, and new atypical drugs versus clozapine, in people with schizophrenia responding poorly to, or intolerant of, current drug treatment. Health Technol Assess. 10: 1-165. Link: http://bit.ly/3s1Vi6A

2. Regen F, Herzog I, Hahn E, Ruehl C, Le Bret N, et al. (2017) Clozapine-induced agranulocytosis: Evidence for an immune-mediated mechanism from a patient-specific in-vitro approach. Toxicol Appl Pharmacol. 316: 10-16. Link: http://bit.ly/3vEw3tx

3. Ponsford M, Castle D, Tahir T, Robinson R, Wade W, et al. (2018) Clozapine is associated with secondary antibody deficiency. Br J Psychiatry. 27: 1-7. Link: http://bit.ly/38TMHLP

4. Holding S, Khan S, Sewell WA, Jolles S, Dore PC (2015) Using calculated globulin fraction to reduce diagnostic delay in primary and secondary hypogammaglobulinaemias: results of a demonstration project. Ann Clin Biochem. 52: 319-326. Link: http://bit.ly/3cKCPFb

5. James PM (2020) Clinical and laboratory characteristics of clozapine-treated patients with schizophrenia referred to a national immunodeficiency clinic reveals a B-cell signature resembling common variable immunodeficiency (CVID). J Clin Pathol. 73: 587-592. Link: http://bit.ly/3cGVIZT

6. Karbownik MS, Gunerka P, Turowski $P$, Wieczorek M, Kowalczyk E, et al (2018) Activation of phosphoinositide 3-kinase delta by antipsychotic drugs: Preliminary results. Pharmacol Rep. 70: 346-349. Link: http://bit.ly/2P7SFI5

7. Karbownik MS, Szemraj J, Wieteska $Ł$, Antczak A, Górski P, et al. (2016) Antipsychotic drugs differentially affect mRNA expression of genes encoding the neuregulin 1-downstream ErbB4-PI3 K pathway. Pharmacology. 98: 4-12. Link: http://bit.ly/3bWMQ2S

8. Law AJ, Wang Y, Sei Y, O'Donnell P, Piantadosi P, et al. (2012) Neuregulin 1-ErbB4-PI3K signaling in schizophrenia and phosphoinositide 3-kinase-p1108 inhibition as a potential therapeutic strategy. Proc Natl Acad Sci U S A. 109 12165-12170. Link: http://bit.ly/3txS63a

9. Abdelrasoul H, Werner M, Setz CS, Okkenhaug K, Jumaa H (2018) PI3K induces B-cell development and regulates B cell identity. Sci Rep. 8: 1327. Link: http://bit.ly/380mJZZ

10. Clark MR, Mandal M, Ochiai K, Singh H (2014) Orchestrating B cell lymphopoiesis through interplay of IL-7 receptor and pre-B cell receptor signalling. Nat Rev Immunol. 14: 69-80. Link: http://bit.ly/3qYxQFW

11. Coulter TI, Chandra A, Bacon CM, Babar J, Curtis J, et al. (2017) Clinical spectrum and features of activated phosphoinositide 3-kinase d syndrome: a large patient cohort study. J Allergy Clin Immunol. 139: 597-606. Link: http://bit.ly/2P21oWf 